\title{
Entre a linguística e a literatura: percursos interdisciplinares
}

\author{
Maurício Silva*
}

\begin{abstract}
Resumo
O presente artigo trata da interdisciplinaridade entre a linguística e a literatura em dois níveis distintos de interação: um nível que parte da linguística para se chegar à literatura e que, dada sua natureza, situa-se num âmbito geral da educação; e um nível que parte da literatura para se chegar à linguística, em que trataremos de questões relacionadas à pesquisa imanente do texto literário, dentro de uma perspectiva da Análise do Discurso.

Palavras-chave: Linguística; literatura; ensino, interdisciplinaridade.
\end{abstract}

\section{Between linguistics and literature: interdisciplinary courses}

\begin{abstract}
This article deals with the interdisciplinarity between linguistics and literature in two distinct levels of interaction: a level that part of linguistics to arrive at the literature and that, given their nature, situated in a framework of general education; and a level of the literature to arrive at language, in which we will address issues related to the immanent study of literary texts, within a perspective of discourse analysis.

Keywords: Linguistics, literature, teaching, interdisciplinarity.
\end{abstract}

\section{Introdução}

Quando se fala em interdisciplinaridade, de modo geral, pressupõe-se uma determinada metodologia - seja ela de ensino, científica ou de outra natureza -, buscando articular um determinado cabedal teórico a uma prática condizente, com o objetivo de se chegar a determinados resultados. Relacionar, nesse contexto, áreas tão próximas, mas com especificidades tão singulares, como a linguística e a literatura, é, por isso mesmo e desde o início, um desafio.

Sem queremos, aqui, oferecer um método propriamente dito, de articulação interdisciplinar entre elas, buscaremos refletir sobre algumas questões de fundo, que - estas, sim - podem servir de base para a eleição e aplicação de uma determinada metodologia. Desse modo, o presente artigo tratará da interdisciplinaridade entre linguística e literatura em dois níveis distintos de interação: um nível que parte da linguística para se chegar à literatura e que, dada sua natureza, situa-se mais num âmbito geral da educação do que num âmbito específico das pesquisas linguísticas: nesse sentido, privilegiaremos conceitos como os de educação linguística e letramento literário; e um nível que parte da literatura para se chegar à linguística, em que trataremos de questões relacionadas à pesquisa imanente do texto literário, dentro de uma perspectiva da Análise do Discurso.

Buscando, assim, articular todos esses "saberes", objetivamos conferir maior capilaridade às infinitas conexões que áreas distintas do saber naturalmente já possuem, além de contribuirmos para uma reflexão mais aprofundada e contínua acerca dos possíveis enlaces entre duas perspectivas de abordagem do texto tidas, quase sempre, como coirmãs: a abordagem linguística e a abordagem literária.

\section{Linguística e literatura: um diálogo possível}

De modo geral, pensar os possíveis caminhos que promovem a interação entre os estudos linguísticos e os literários pressupõe, num primeiro momento, refletir sobre o conceito - ainda não de todo preciso, mas bastante funcional - de educação linguística, conceito que, como o próprio termo sugere, diz respeito a outras categorias diversas, mas correlatas - de pensamento e análise, como as de competência, domínio, interação linguísticas etc. Portanto, pensar nessa relação interdisciplinar pode nos remeter, a rigor, a uma ação pedagógica voltada especificamente para o domínio amplo da competência linguageira do sujeito-falante.

Há, evidentemente, várias maneiras de se alcançar esse domínio, de acordo com o contexto em que a educação linguística é aplicada, o sujeitofalante para o qual ela se volta, os métodos utilizados na sua aplicação etc. De modo geral, há que se considerar - por exemplo, no que compete ao ensino da língua portuguesa - pelo menos três possibilidades de interconexão, sem as quais o percurso que leva do processo educativo

* Universidade Nove de Julho (SP). Endereço eletrônico: maurisil@ gmail.com 
relacionado ao domínio da linguagem à efetiva competência linguística torna-se, com certeza, mais difícil: a relação entre o ensino da língua e a leitura, na medida em que, grosso modo, ler auxilia no uso da língua; a relação entre o ensino da língua e a escrita, uma vez que o exercício da escrita tem repercussões positivas no domínio da comunicação linguística; e a relação entre o ensino da língua e a adoção de uma concepção sociointeracionista da linguagem, tendo como um dos pontos de partida os preceitos metodológicos da Linguística da Enunciação (FLORES; TEIXEIRA, 2006).

Além disso, na delicada e complexa questão do ensino de língua portuguesa, há de se considerar uma série de variáveis: quando se deve ensinar a língua portuguesa, para quem ensiná-la, o que se deve ensinar etc. Não pretendemos evidentemente discutir todas essas variáveis, o que demandaria uma série de considerações alheias ao objetivo principal deste artigo. Apenas a título de ilustração, não nos parece possível discutir, por exemplo, qualquer uma dessas questões sem levar em consideração, num sentido lato, os conceitos de alfabetização, letramento, ensino de gramática, preconceito linguístico e muitos outros. Aliás - sem entrar no mérito do assunto, bastante debatido tanto histórica quanto conceitualmente (MARCUSCHI, 2000) -, o fundamento geral de todas essas questões encontra-se, a nosso ver, num antigo embate entre linguistas, adeptos da descrição idiomática, e gramáticos, adeptos da prescrição idiomática; ou, em outros termos, entre os defensores do uso e os da norma da língua portuguesa (SILVA, 2010).

Durante longo tempo, o ensino da língua portuguesa pautou-se por uma metodologia pedagógica que tinha como referência, do ponto de vista teórico, a gramática normativa e, do ponto de vista prático, o exercício mecânico de repetição de normas e regras gramaticais em geral descontextualizadas. Em razão do distanciamento que quase sempre existiu entre as diretrizes pedagógicas institucionalizadas e a prática do ensino do vernáculo, os sucessivos dispositivos legais formulados com o intuito de possibilitar uma nova prática pedagógica (como a Nomenclatura Gramatical Brasileira, a Lei de Diretrizes e Bases da Educação e uma série de decretos-leis relativos a matérias afins) não resultaram em alteração substancial do esquema escolar tradicionalmente adotado (MOURA NEVES, 1994).

Foi, portanto, somente com o avanço dos estudos da linguagem verbal, responsáveis pelo deslocamento de uma abordagem assentada na linguística da palavra para uma abordagem direcionada para a linguística do texto e/ou da situação comunicativa (Linguística Textual, Pragmática, Gramática Funcional etc.) que as práticas pedagógicas de fato avançaram no sentido de promover uma inflexão no processo de ensino do português: passou-se, grosso modo, de um estágio normativista do estudo gramatical para uma abordagem descritivista, como se pode constatar, por exemplo, nos pressupostos teóricos veiculados pelos Parâmetros Curriculares Nacionais (MINISTÉRIO DA EDUCAÇÃO/SECRETARIA DE EDUCAÇAO FUNDAMENTAL, 2000). Com efeito, embora estudos nessa direção já fossem realizados há décadas, não se pode negar o impulso dado à chamada educação linguística pelos referidos Parâmetros, os quais procuraram estabelecer novos protocolos de atuação docente diante dos desafios impostos pelo emprego concreto da língua portuguesa por seu usuário nativo, sobretudo no que se refere ao famigerado ensino da gramática, buscando garantir ao alunado o acesso aos diversos saberes linguísticos, necessários para o exercício da cidadania, não se esquecendo do vínculo, inalienável, entre esses saberes e a participação social plena.

De fato, mais do que o ensino passivo da gramática da língua - no sentido que esse conceito possa ter de um processo de manipulação descontextualizada de mecanismos metalinguísticos -, o ensino do idioma materno deve pautar-se pela eficácia de seu uso nas situações de intercomunicação, pela luta contra a estigmatização das variantes dialetais (MATTOS; SILVA, 2004) e, sobretudo, pelo largo domínio dos processos discursivos. Nem sempre, contudo, essa ideologia prevaleceu na escola e, particularmente, no ensino da língua portuguesa. Durante muito tempo, como se sabe, a educação linguística se limitou - no que compete ao ensino do português - às chamada aulas de gramática nacional (PILETTI, 1987), consolidando, na prática, uma verdadeira "tradição normativa", ao fundamentar considerações e formulações gramaticais, por intermédio das quais prevaleceriam formas pretensamente corretas de falar (PETTER, 2002).

Assim, embora determinados teóricos considerem que a escola deva desempenhar o papel de ensinar a língua padrão, a fim de que o aluno alcance esse nível de linguagem - registro, aliás, que ainda denota maior prestígio social (BECHARA, 2000) - , alguns estudiosos da linguagem preferem condenar como preconceito a 
não incorporação de construções gramaticais próprias da oralidade ou de um falar mais atual e, por conseguinte, contrário ao que prescrevem as gramáticas tradicionalmente normativas, o que, no limite, faz emergir não outra língua ou outra gramática, mas uma concepção renovada de padrão linguístico: "haveria certamente muitas vantagens no ensino de português se a escola propusesse como padrão ideal de língua a ser atingido pelos alunos a escrita dos jornais ou dos textos científicos, ao invés de ter como modelo a literatura antiga" (POSSENTI, 1996, p. 41).

No final das contas, o que o autor propõe é não abandonar de vez o ensino da gramática, mas alterar prioridades, adotando como conteúdo curricular nas escolas fatos linguísticos que os alunos ainda não sabem ou deveriam saber no domínio do registro culto e não toda a gramática normativa. Para autores que defendem um ensino gramatical assentado na experiência real (leia-se, em determinados contextos, oral) da linguagem, a gramática normativa revela-se particularmente preconceituosa, na medida em que, ideologicamente, impõe-se como lugar de representação das contradições presentes numa sociedade dividida entre os que supostamente sabem a língua e os que tentam aprendê-la (SOARES, 2001), mas - e isso é o que realmente importa - sem procurar resolvê-las.

Com a mudança, presentemente, da perspectiva linguística que passa da abordagem da linguagem verbal, primeiro, da palavra para a frase e, depois, da frase para o texto, houve uma alteração também no enfoque do ensino do português, que passou da gramática normativa para a competência pragmática, uma vez que, como já se disse,

as gramáticas que nos explicam as
construções frasais mostram-se
inadequadas para a descrição da
combinação dessas unidades [frásicas] num
contexto mais amplo [...] Embora as frases
façam parte do texto, a análise minuciosa
de cada uma delas em nada contribui para
a nossa compreensão do texto global
(TATIT, 2002, p. 187).

Com efeito, pelo que foi visto até aqui, atualmente a tendência pedagógica, no que diz respeito ao ensino da língua portuguesa, se faz no sentido de privilegiar perspectivas interdisciplinares e, sobretudo, as atividades epilinguísticas (em oposição às metalinguísticas), muito mais apropriadas à utilização da gramática descritiva - e, sobretudo, funcional - da língua do que a normativa.

Nesse sentido, nada nos parece mais apropriado do que, ampliando o sentido que buscamos dar aqui à ideia de interdisciplinaridade, aproximemos os estudos da linguagem aos estudos da literatura, partindo da noção de educação linguística para chegar à de letramento literário, completando a outra face de uma mesma moeda.

$\mathrm{Na}$ tradição luso-cristã, a partir dos dispositivos legais estabelecidos para a educação das colônias pelo governo de D. José I - na pessoa de seu ministro, o Marquês de Pombal -, o estudo da literatura (na época, chamado de poética) nasce vinculado ao estudo da gramática e da retórica, compondo assim o universo das ciências das palavras (ALMEIDA, 2008). De certo modo - se considerarmos uma série de instrumentos "pedagógicos", relacionados ao ensino de literatura, como os livros didáticos, os currículos escolares, os planejamentos didáticos e outros -, tal tradição mantém-se até hoje, a despeito dos sistemáticos ataques que tem sofrido (ZILBERMAN, 1988; ZILBERMAN; SILVA, 2008).

Hoje em dia, cada vez mais, torna-se imperativa uma política educacional que se fundamente, prioritariamente, no estimulo à leitura, em especial à leitura de literatura, principalmente por ser esse um gênero discursivo que, de modo mais abrangente, trata não apenas da infinita variabilidade linguística, mas também da representação estética de um incomensurável universo cognitivo. Por isso, para Regina Zilberman e Ezequiel Silva,

compete hoje ao ensino da literatura não mais a transmissão de um patrimônio já constituído e consagrado, mas a responsabilidade pela formação do leitor. A execução dessa tarefa depende de se conceber a leitura não como o resultado satisfatório do processo de alfabetização $e$ decodificação de matéria escrita, mas como atividade propiciadora de uma experiência única com o texto literário (ZILBERMAN; SILVA, 2008, p. 23).

Particularmente no âmbito do ensino, uma política de incentivo e promoção da leitura deve, antes de tudo, levar em consideração um amplo processo de letramento literário, que envolva desde os mediadores de leitura e instâncias educacionais 
até instituições diretamente relacionadas ao livro, como bibliotecas e editoras. Enfim, uma política que envolva os vários agentes de produção, promoção e veiculação da literatura. Incentivar o hábito de leitura e promover o texto literário como centro integrador de conhecimentos diversos tornase, assim, uma maneira de reconfigurar a prática da leitura, a partir do conceito nuclear, aqui aludido, de letramento literário, que passa a atuar, então, como instrumento de desenvolvimento da leitura na escola, além de ampliar as possibilidades do emprego da escrita e a capacidade crítica do aluno diante da sociedade em que se insere.

O letramento - termo que, de maneira geral, denota "o resultado da ação de ensinar ou de aprender a ler e escrever: o estado ou a condição que adquire um grupo social ou um indivíduo como consequência de ter-se apropriado da escrita" (SOARES, 2004, p.18) - conheceu, desde sua formulação, desdobramentos diversos, sendo possível falar em letramento não num sentido absoluto do termo, mas em letramentos, no plural. Rildo Cosson, por exemplo, pesquisou, em especial, o chamado letramento literário, particularmente voltado aos "usos" da literatura em sala de aula. Em seu livro sobre o assunto, o autor propõe um trabalho que leve o aluno a se tornar letrado, apropriando-se da leitura de literatura na escola. Assim, segundo Cosson,

ser leitor de literatura na escola é mais do que fruir um livro de ficção ou se deliciar com as palavras exatas da poesia. $E$ também posicionar-se diante da obra literária, identificando e questionando protocolos de leitura, afirmando ou retificando valores culturais, elaborando $e$ expandindo sentidos. Esse aprendizado crítico da leitura literária [...] não se faz sem o encontro pessoal com o texto enquanto princípio de toda experiência estética (COSSON, 2006, p. 120).

Não sem razão, uma das maiores discussões em torno desse tema é como se dá o ensino da literatura, já que, convém lembrar, os textos que estão na escola nem sempre estão também presentes no cotidiano do aluno e vice-versa. Isso tem relação direta com o que chamamos aqui de diálogo possível entre linguística e literatura: por meio do estudo da linguagem chega-se à literatura e viceversa; evidentemente, não se trata de um percurso direto, sem percalços, mas de um percurso indireto, mais amplo, cheio de idas-e-vindas, carregados de entroncamentos e desvios, e, por isso, mesmo, mais interessante e promissor. Desse modo, para que o aluno possa se formar plenamente como cidadão crítico e consciente, faz-se necessário - entre outras coisas - que a escola promova uma prática de leitura interdisciplinar, ampla, sobretudo relacionada à realidade desse leitor. Isso, a nosso ver, levaria ao desenvolvimento da própria competência discursiva do aluno, criando, além disso, condições de aprendizagem e de socialização a partir do contato direto com a literatura e seus diversos promotores - eis aí um diálogo possível e frutífero entre as duas áreas do saber aqui aludidas: oferecer ao leitor uma gama variada de possibilidades de interação com os textos literários resulta também nos desenvolvimento de sua capacidade plena de comunicação escrita, estimulando o conhecimento de culturas variadas e resgatando a consciência integradora das manifestações interculturais. Enfim, considerar a linguística e a literatura como áreas articuladoras de aspectos diversos do conhecimento, promovendo a interdisciplinaridade, devem ser alguns dos propósitos da educação, já que todo diálogo, como alerta Paulo Freire, é também um caminho para a conscientização e para a libertação (FREIRE, 2009), em particular - completaríamos - no contexto discursivo.

\section{Literatura e linguística: outro diálogo possível}

Um caminho "inverso" ao que foi proposto acima - isto é, que parta da literatura em direção à linguística, mas sem rigidez no percurso - é também possível: nesse aspecto, propomo-nos a tratar de questões relacionadas tanto à análise imanente do texto (que não prescinde de considerações de natureza linguística) quanto à aproximação entre a literatura e alguns pressupostos da Análise do Discurso, que compartilha de modo evidente seus métodos de trabalho entre a literatura e os estudos da linguagem.

Do ponto de vista metodológico, esse é um percurso que projeta uma intersecção dos discursos ficcional e teórico, numa perspectiva restrita, e da literatura e linguística, numa perspectiva genérica. Promove, portanto, a interação entre, pelo menos, duas vertentes dos estudos linguísticos (discursiva e historiográfica) e os estudos teóricos de análise literária. Especificamente, sua base teórica apoia-se, ao mesmo tempo, na Historiografia Linguística, enfatizando a história externa da língua a partir da 
ótica dos literatos brasileiros (por exemplo, enfatizando determinado ideário linguístico); e em alguns pressupostos teóricos estabelecidos pela Análise do Discurso, na medida em que esta nos permite observar conceitos explícitos acerca da linguagem advogados por esses autores (por exemplo, observando determinado discurso metalinguístico). Semelhante procedimento não dispensa, no limite, a interação entre o universo da educação e as múltiplas linguagens institucionalizadas ou não - que compõem o mundo contemporâneo, entendendo por linguagens um amplo universo de manifestações semiológicas, dentre as quais encontra-se a própria literatura

Como dissemos antes, buscaremos aqui dar destaque às possíveis conexões entre os estudos literários e a Análise do Discurso, como forma de promover a interdisciplinaridade e valorizar os diálogos possíveis entre as duas áreas de abordagem do texto.

As relações entre a linguística e a literatura vêm de longa data: alguns teóricos da literatura ainda lutavam, em meados do século $\mathrm{XX}$, por estabelecer uma teoria que tornasse a análise formalista algo mais sistemático e incisivo (TODOROV, 1965), o que foi mais bem formulado pelos estruturalistas, sobretudo a partir da década de 1960, quando se inicia um movimento de se aplicar à análise literária alguns métodos fundamentais da Linguística Estrutural de Saussure; em muitos aspectos, o estruturalismo aproxima-se das ideias dos formalistas russos (com, por exemplo, o Círculo Linguístico de Praga, tendo à frente Roman Jakobson), enfatizando ainda os estudos semióticos (MACHADO, 2007). A partir do desenvolvimento do estruturalismo, outras disciplinas - que, fundamentalmente, conciliavam literatura e linguística - foram surgindo, como a narratologia (BARTHES, 1970). Um pouco como extensão dessa tendência, um pouco como reação à sua rigidez, alguns teóricos promoveram uma "passagem" dos métodos analíticos fundamentados, grosso modo, na língua para aqueles fundamentados no discurso, tendência que teve em Bakthin uma das figuras mais expressivas, na medida em que defendia que "a linguagem era um campo de luta ideológica, não um sistema monolítico; os signos eram, na verdade, o próprio veículo material da ideologia, já que sem eles não poderiam existir valores ou ideias" (EAGLETON, s.d., p. 125).

Com efeito, o quadro da teoria literária que até meados do século $\mathrm{XX}$ parece ter permanecido excessivamente subserviente às abordagens imanentistas - modificou-se bastante a partir das teorias pós-estruturalistas (LODGE, 1988; YOUNG, 1987), principalmente a partir das teorias formuladas por Bakhtin, que vincula os atos de enunciação à situação social em que os mesmos se inscrevem. No rastro dessa ideia, o próprio teórico russo pôde formular um novo conjunto de conceitos, a partir dos quais sugere a impossibilidade de se estudar uma obra literária fora de sua contextualização social (BAKHTIN, 1988, 1990). De fato, para Bakhtin, os estudos literários devem ser considerados uma manifestação prática do conceito de ideologia (TODOROV, 1981; LODGE, 1990), sendo a literatura uma criação ideológica que se concretiza no processo de relação social, daí a necessidade de se levar em conta aspectos exteriores na tarefa de interpretação crítica:

social intercourse is the medium in wich the ideological phenomenon first acquires its specific existence, its ideological meaning, its semiotic nature. All ideological things are objects of social intercourse, not objects of individual use, contemplation, emotional experience, or hedonistic pleasure [...] The work of art, like every other ideological product, is an object of intercourse. It is not the individual, subjective psychic states it elicits that are important in art, but rather the social connections, the interactions of many people it brings about (BAKHTIN, 1978, p. 08-11).

Assim sendo, parece-nos necessário, atualmente, adotar uma metodologia analítica que, aproveitando direta ou indiretamente a heurística bakhtiniana, estabeleça novos parâmetros epistemológicos para a relação entre literatura e linguística, num sentido estrito, bem como, num sentido mais amplo, entre literatura e sociedade.

No quadro da Análise do Discurso de linhagem francesa, as contribuições foram e têm sido, igualmente, consideráveis. A origem desse percurso encontra-se, ainda uma vez, nos pressupostos teóricos do estruturalismo, já que a relação entre literatura e linguística - em especial no que concerne ao discurso - já se manifestava, in germine, na observação que Barthes faz sobre as infinitas espécies de narrativas existentes, ao observar a necessidade de se formular uma linguistique du discours (BARTHES, 1977). Num sentido mais amplo, as teorias formuladas, posteriormente, pela Estética da Recepção 
defendem a ideia de que toda interpretação, ao invés de comunicar ao leitor o sentido do texto, deve preocupar-se em explicitar, antes, as "conditions de constituition du sens” (ISER, 1997, p. 33), sugerindo a consideração do contexto como um elemento intrínseco ao texto, como parte essencial de sua estrutura. Por isso, aliando essa perspectiva àquela defendida pela Análise do Discurso francesa, acreditamos dever fazer parte da obra literária tanto os "suportes materiais da enunciação", isto é, seus elementos técnicos (escrita, tipografia, veículo etc.), quanto a "situação de enunciação", isto é, suas circunstâncias (período, lugar, indivíduo enunciador etc.), já que o contexto "informa em profundidade a enunciação literária" (MAINGUENEAU, 1995, p. 101). O que, em última instância, assinala a importância do que a Análise do Discurso convencionou chamar de condições de produção do texto literário (BRANDÃO, 1997; GADET; HAK, 1993; MAINGUENEAU, 1997; ORLANDI, 1994), expressão vertida, ainda nas palavras de Maingueneau, para condições de enunciação, modo pelo qual a ideia de contexto - e sua importância para a obra literária - torna-se mais explicita: "as condições de enunciação do texto literário não são uma estrutura contingente da qual este poderia se libertar, mas estão indefectivelmente vinculadas a seu sentido" (MAINGUENEAU, 1995, p. 19); ou, em outros termos, as "circunstâncias da enunciação [devem ser] compreendidas não como um entorno contingente do enunciado, mas como um dos componentes de seu ritual" (MAINGUENEAU, 1995, p. 66).

Em suma, a constituição de um texto como literário depende, basicamente, de uma série de questões ligadas, por contraste, a outros elementos próprios do universo linguístico, que acabam instituindo esse texto como expansão, restrição ou desvio de normas linguísticas definidas, resultando na consolidação do discurso como ficção.

\section{Conclusão: diálogos prováveis}

Qualquer aproximação que, no âmbito dos estudos acadêmicos, se faça entre os universos literário e linguístico resultará, com certeza, em ganhos múltiplos para ambas as áreas de pesquisa, enriquecendo nossa compreensão daquele que é, no final das contas, seu objeto comum de observação, análise e interpretação - o texto, num sentido lato.

Com desusada pertinácia, muitos escritores voltam-se para o problema da língua empregada num determinado país, preocupados, por exemplo, com seu funcionamento dentro do discurso literário, quase sempre a partir de dois pontos de vista distintos, porém complementares: de um lado, uma fatura literária em que se pode entrever, sob vários aspectos, a concretização de um ideário linguístico; de outro lado, formulações teóricas acerca da linguagem, norteando esse mesmo ideário e manifestando-se, sobretudo, por meio de um determinado discurso metalinguístico. Assim, questões que, na aparência, são de natureza puramente linguísticas, extrapolam, na verdade, tal perspectiva, quando então se busca conceber a linguagem não como objeto ideologicamente neutro, mas como manifestação intencional de um sujeito produtor de discursos e detentor de códigos de funcionamento e usos da própria língua. O inverso é, também, verdadeiro, com a literatura atuando de modo a precisar aspectos da língua nem sempre evidentes numa abordagem privilegiadamente linguística.

Como partimos da educação, ao fazer nossas primeiras considerações acerca das possibilidades de um trabalho interdisciplinar entre os estudos literários e linguísticos, parece justo que voltemos, depois de trilhado esse fecundo percurso, à questão da educação: de maneira geral, dizemos que a dimensão pedagógica dos estudos literários e linguísticos só é plenamente alcançada acreditamos - por meio da prática da interdisciplinaridade: é no encontro entre áreas distintas, mas coirmanadas, do saber humano que o conhecimentos atinge, por assim dizer, sua plenitude, tornando-se não apenas fonte de prazer, mas também de intervenção social em benefício da cidadania plena. Tudo isso tem a ver, em última instância, com o exercício da leitura, num sentido amplo, tal como prescreve, de maneira simples e objetiva, a pedagogia crítica:

os estudantes precisam aprender a ler não como um processo de submissão à autoridade do texto, mas como um processo dialético de compreensão, de crítica e de transformação. Eles precisam escrever $e$ reescrever as histórias nos textos que leem, de forma a serem capazes de identificar $e$ desafiar, se for o caso, as maneiras pelas quais tais textos funcionam ativamente para construir suas histórias e vozes. Ler um texto deve ser uma maneira de aprender a fazer escolhas, a construir uma voz e a localizar a si próprios na história (MCLAREN, 2000, p. 38). 
Não sem razão, é a consciência crítica do ensino da língua - por exemplo, ao promover uma revisão do modo como a linguagem é trabalhada em sala de aula, em especial da maneira como a gramática é instrumentalizada, em prol da renovação de seus sentidos - que poderá levar o aluno a se tornar um usuário consciente das possibilidades do idioma. $\mathrm{O}$ mesmo se poderá dizer acerca da literatura e seu ensino: se um dos objetivos da escola é formar o aluno como cidadão crítico e autônomo, um estudo consciente da literatura pode ser um dos instrumentos que, sem dúvida, potencializa a concretização desse objetivo: a articulação interdisciplinar entre a linguística e a literatura pode ser um dos mais eficazes caminhos para isso.

\section{Referências}

ALMEIDA, Anita Correia Lima de. "Aulas régias no império colonial português: o global e o local". In: LIMA, Ivana Stolze \& CARMO, Laura do. História Social da Língua Nacional. Rio de Janeiro, Casa de Rui Barbosa, 2008, p. 65-90.

BAKHTIN, Mikhail/MEDVEDEV, P. The Formal Method in Literay Scholarship. A Critical Introduction to Sociological Poetics. London, Johns Hopkins, 1978

BAKHTIN, Mikhail. Marxismo e Filosofia da Linguagem. Problemas Fundamentais do Método Sociológico na Ciência da Linguagem. São Paulo, Hucitec, 1988.

Questões de Literatura e de Estética. A Teoria do Romance. São Paulo, Hucitec, 1990.

BARTHES, Roland et alii. Poétique du Récit. Paris, Seuil, 1977.

BARTHES etalii. Estructuralismo y Literatura. Ediciones Nueva Visión, Buenos Aires, 1970.

BECHARA, Evanildo. Ensino da Gramática. Liberdade? Opressão? São Paulo, Ática, 2000.

BRANDÃO, Helena H. Nagamine. Introdução à Análise do Discurso. Campinas, Unicamp, 1997.
COSSON, Rildo. Letramento Literário. São Paulo, Contexto, 2006.

EAGLETON, Terry. Teoria Literária. Uma Introdução. São Paulo, Martins Fontes, s.d.

FLORES, Valdir do Nascimento e TEIXEIRA, Marlene. Introdução à Lingüística da Enunciação. São Paulo, Contexto, 2006.

FREIRE, Paulo. Pedagogia da Autonomia. Saberes Necessários à Prática Educativa. São Paulo, Paz e Terra, 2009.

GADET, Françoise \& HAK, Tony (orgs.). Por uma Análise Automática do Discurso. Uma Introdução à Obra de Michel Pêcheux. Campinas, Unicamp, 1993.

ISER, Wolfgang. L'Acte de Lecture. Théorie de l'Effet Esthétique. Sprimont, Mardaga, 1997.

LODGE, David. After Bakhtin. Essays on Fiction and Criticsm. London/New York, Routledge, 1990.

LODGE, David (ed.). Modern Criticism and Theory. A Reader. London/New York, Longman, 1988.

MACHADO, Irene. O Filme que Saussure não viu. O Pensamento Semiótico de Roman Jakobson. São Paulo, Horizonte, 2007.

MAINGUENEAU, Dominique. O Contexto $d a$ Obra Literária. Enunciação, Escritor, Sociedade. São Paulo, Martins Fontes, 1995.

MAINGUENEAU, Dominique. Novas Tendências em Análise do Discurso. Campinas, Pontes, Unicamp, 1997.

MARCUSCHI, Luiz Antônio. "A gramática e o ensino de língua no contexto da investigação lingüística". In: BASTOS, Neusa Barbosa (org.). Discutindo a Prática Docente em Língua Portuguesa. São Paulo, IP-PUC, 2000, p. 83-94.

MATTOS E SILVA, Rosa Virgínia. "O Português são Dois"... Novas Fronteiras, Velhos Problemas. São Paulo, Parábola, 2004.

MCLAREN, Peter. Multicuralismo Revolucionário. Pedagogia do Dissenso para o Novo Milênio. Porto 
Alegre, Artmed, 2000.

MINISTÉRIO DA EDUCAÇÃO / SECRETARIA DE EDUCAÇAO FUNDAMENTAL. Parâmetros Curriculares Nacionais: Língua Portuguesa. Rio de Janeiro, DP\&A, 2000.

MOURA NEVES, Maria Helena de. Gramática na Escola. São Paulo, Contexto, 1994.

ORLANDI, Eni Puccinelli (org.). Gestos de Leitura. Da História no Discurso. Campinas, Unicamp, 1994.

PETTER, Margarida. "Linguagem, Língua, Lingüística". In: FIORIN, J. Luiz (org.). Introdução à Lingüística. São Paulo, Contexto, 2002, p. 11-24.

PILETTI, Nelson. "Evolução do Currículo do Curso Secundário no Brasil". Revista da Faculdade de Educação, Universidade de São Paulo, São Paulo, Vol. 13, No. 02: 27-72, jul.-dez. 1987.

POSSENTI, Sírio. Por Que Não Ensinar Gramática na Escola. Campinas, Mercado de Letras, 1996.

SILVA, Maurício. "Entre o uso e a norma: uma introdução à gramaticografia da língua portuguesa no Brasil da passagem do século". In: SIMÕES, Darcilia \& MENESES, Eliana de Melo (orgs.). Linguagens, criatividade e sentidos: pelos percursos da semiótica do cotidiano. Rio de
Janeiro, Dialogarts/UERJ, 2010, p. 204-218.

SOARES, Magda. Linguagem e Escola. Uma Perspectiva Social. São Paulo, Ática, 2001. . Letramento um Tema em Três Gêneros. Belo Horizonte: Autêntica, 2004.

TATIT, Luiz. "A abordagem do texto". In: FIORIN, J. Luiz (org.). Introdução à Lingüística. São Paulo, Contexto, 2002, p. 186-209.

TODOROV, Tzvetan. Mikhaïl Bakhtine. Le Principe Dialogique. Paris, Seuil, 1981.

TODOROV, Tzvetan (org.). Théorie de la Littérature. Textes dês Formalistes Russes. Paris, Seuil, 1965

ZILBERMAN, Regina (org.). Leitura em Crise na Escola: As Alternativas do Professor. Porto Alegre, Mercado Aberto, 1988.

ZILBERMAN, Regina e SILVA, Ezequiel Theodoro da. Literatura e Pedagogia. Ponto \& Contraponto. São Paulo/Campinas, Global/ALB, 2008.

YOUNG, Robert (ed., int.). Untying the Text: A Pos-Structuralist Reader. London/New York, Routledge, 1987.

\section{Sobre o autor}

Maurício Silva é doutor em Letras Clássicas e Vernáculas pela Universidade de São Paulo e professor do Programa de Mestrado e Doutorado em Educação da Universidade Nove de Julho.

Recebido em maio de 2014.

Aprovado em maio de 2015. 